\title{
FRONTEIRA DE EFICIÊNCIA DOS CLUBES DE FUTEBOL DO CAMPEONATO BRASILEIRO SÉRIE "A" DE 2012
}

FRONTIER EFFICIENCY OF SPORTS CLUBS SOCCER CAMPEONATO BRASILEIRO

SÉRIE "A" 2012

\section{Idalberto José Neves Júnior}

ineves@ucb.br

Universidade Católica de Brasília, Brasília/DF, BRASIL

\section{Simone Alves Moreira}

simoneucb@gmail.com

Banco do Brasil, Brasília/DF, BRASIL

\section{André Soares de Souza Prado}

andre prado@outlook.com

Universidade Católica de Brasília, Brasília/DF, BRASIL

\section{Luan Junio Ferreira da Silveira}

luanjunio13@gmail.com

Universidade Católica de Brasília, Brasília/DF, BRASIL

\section{Resumo}

Com a estabilidade econômica dos últimos anos a indústria do futebol passou a movimentar bilhões de reais anualmente, registrando um acentuado crescimento nos últimos 10 anos. Mediante esse contexto o presente estudo busca analisar quais os clubes de futebol podem ser considerados eficientes no Campeonato Brasileiro 2012 quando observados sua pontuação, as receitas geradas e as despesas realizadas, por meio da Análise Envoltória de Dados, com auxilio do software SIAD v.3. Como principal resultado, verificou-se que o Grêmio foi o clube mais eficiente dentre os clubes analisados no período, enquanto o Botafogo foi o menos eficiente.

Palavras-chave: Receitas. Despesas. Eficiência. Contabilidade. Futebol.

\section{Abstract}

With the economic stability of recent years the football industry began to move billions of dollars annually, registering a sharp increase in the last 10 years. Through this context, the present study seeks to examine how football clubs can be considered efficient in the Campeonato Brasileiro 2012 when considering your score, the revenue generated and expenses incurred by means of data envelopment analysis, with the aid of software SIAD v.3. As the main result, we found that the club is the faded more efficiently analyzed from the clubs during the period while the Botafogo was the least efficient.

Keywords: Recipes. Expenses. Efficiency. Accounting. Football. 


\section{Introdução}

A primeira partida de futebol realizada no Brasil, foi organizada por Charles Miller em 1895 e se tratava apenas de uma divertida forma de praticar atividades físicas e de reunir amigos para entretenimento, porém em 1933 este panorama foi modificado, o futebol se profissionalizou. Nesse sentido iniciou-se uma nova era no futebol brasileiro, São Paulo e Santos disputaram o que ficou conhecido como a primeira partida de futebol profissional da história, vencida pelo São Paulo por 5 a 1 (RODRIGUES, 2013).

Com a criação do primeiro campeonato e com a profissionalização do futebol em 1933, o esporte passou a ser praticado por diversas pessoas no Brasil e os clubes se transformaram em verdadeiras empresas, pois passaram a gerar emprego para seus atletas e produzir receitas e rendas para si.

Com a estabilidade econômica dos últimos anos, esta grande indústria do futebol passou a movimentar bilhões de reais a todo ano. Segundo Coutinho (2012), dados da Receita Federal demonstram que os vinte clubes que disputaram a série "A" do Campeonato Brasileiro em 2012 faturaram mais de R $\$ 7$ bilhões entre os anos de 2006 e 2010.

Segundo a empresa de consultoria e auditoria BDO (2013) em 2003 o mercado brasileiro de futebol gerou $\mathrm{R} \$ 805$ milhões em receitas, seis anos depois em 2009 registrou crescimento de $140 \%$ atingindo receita de R \$ 1,9 bilhões. Ainda segundo a BDO (2013) os 20 clubes de maiores receitas do futebol brasileiro em 2011 geraram receitas de $\mathrm{R} \$ 2,14$ bilhões, crescimento de $266 \%$ se comparado com 2003.

Silva e Campos Filho (2006) dividem esta indústria em dois grandes consumidores: o torcedor, considerado o consumidor final; e as televisões, patrocinadores e loterias, considerados como consumidores intermediários deste produto, o futebol. O torcedor se caracteriza como um consumidor mais passional, levando em consideração apenas a eficiência esportiva em campo, ao passo que os consumidores intermediários observam também a eficiência financeira dos clubes em que investem seu capital.

Para manter o crescimento do mercado e conquistar títulos em campo, sem aumentar o endividamento que possa comprometer o futuro financeiro dos clubes, seus administradores devem ser eficientes na alocação de recursos.
Hendriksen e Breda (1999, p. 202) destacam que os futuros investidores analisam a eficiência da administração da empresa antes de aplicar seus recursos, eficiência esta definida como capacidade de obtenção máxima de resultados com o mínimo de insumos. Analogia similar pode ser feita aos clubes de futebol, pois com o mínimo de insumos, ou despesas, busca-se um retorno ótimo, seja por meio de receitas ou pontos ganhos em determinado campeonato, que resulte em conquista de título, meta almejada por todos os clubes.

Sobre estudos anteriores é possível evidenciar os resultados das pesquisas realizadas por Dantas e Boente (2011, p. 86) que utilizaram o modelo DEA para medir a eficiência financeira e esportiva dos clubes europeus e evidenciaram que o estudo "corrobora com a sistemática que o desempenho esportivo dentro de campo gera receitas para o clube, ou seja, as duas eficiências são correlacionadas".

Mediante esse contexto tem-se a questão de pesquisa: com a aplicação do modelo de Análise Envoltória de Dados (DEA), quais clubes de futebol podem ser considerados eficientes no Campeonato Brasileiro 2012 quando observados sua pontuação, as receitas geradas e as despesas realizadas?

O presente estudo tem por objetivo geral de analisar a fronteira de eficiência dos clubes de futebol do Campeonato Brasileiro 2012, e como objetivos específicos construir um ranking de eficiências dos clubes analisados, definir metas (targets) para melhoria da eficiência dos clubes considerados ineficientes e definir qual seria a classificação final do Campeonato Brasileiro Série "A" de 2012 após análise DEA.

Para tanto, foram coletadas as demonstrações financeiras nos sites oficiais dos clubes e a pontuação final no campeonato brasileiro de 2012 no site da Confederação Brasileira de Futebol, posteriormente foi realizada a análise com a aplicação do modelo de Análise Envoltória de Dados (DEA), utilizando o software SIAD v.3.0 para medir a eficiência dos clubes brasileiros. 


\section{Referencial Teórico}

\section{Mercado de futebol}

O mercado futebolístico cresceu tanto nos últimos anos que a International Federation of Football History $e$ Statistics (2013), federação internacional especializada em história e estatística do futebol considerou o campeonato brasileiro de 2012 o segundo melhor do mundo, ficando atrás apenas do campeonato espanhol.

Damato (2012) ilustra muito bem este crescimento, frisando que "num país em que a economia evoluiu 2,7\% em 2010, o faturamento dos 14 principais clubes do Brasil cresceu dez vezes mais rapidamente: $27 \%$ ".

Análise feita a partir dos balanços dos 10 clubes com maiores receitas do futebol brasileiro em 2011, demostram uma evolução astronômica em suas receitas, em 2005 apenas dois clubes haviam registrado receitas maiores que $\mathrm{R} \$ 100$ milhões, São Paulo e Santos. Já em 2011, nove dos dez maiores clubes haviam atingido a marca dos $\mathrm{R} \$ 100$ milhões, sendo que entre esses, São Paulo e Corinthians apresentaram receitas maiores que $\mathrm{R} \$ 200$ milhões (SOMOGGI, 2013).

Ainda segundo Somoggi (2013) em 2003 as receitas do mercado brasileiro de futebol somaram $\mathrm{R} \$ 805$ milhões, ao passo que em 2011 as receitas atingiram $\mathrm{R} \$ 2,7$ bilhões, apresentando um crescimento de $335 \%$ em apenas 8 anos.

Ekelund (1998, apud SILVA e CAMPOS FILHO, 2006, p. 198) em seu estudo sobre a rentabilidade das associações de times de futebol, apresentou a evolução do sistema de receitas na indústria do futebol profissional da seguinte forma:

i) Até a década de 50 (A Era do Estádio), onde o principal do negócio era a relação clube-torcedor e ela se dava em torno das entradas nos estádios;

ii) Entre as décadas de 50 70 (A Era da TV Comercial Tradicional), quando as televisões gratuitamente transmitiam os jogos e originam os patrocinadores;

iii) Década de 80 (A Era dos Patrocinadores), quando os patrocinadores passaram a se interessar pelo futebol pela visibilidade proporcionada pelo aumento da audiência; e,

iv) Após a década de 80 (A era da Nova Mídia), quando a televisão e a internet passaram a ser grandes consumidores (intermediários), pagam pelos direitos de transmissão e objetivam o retorno financeiro.

Ou seja, no início o futebol possuía apenas uma fonte de receitas, os ingressos comprados por seus torcedores, como o passar das décadas novos meios de arrecadação surgiram, tais como, receitas com direitos de transmissão de televisão e receitas com publicidade e patrocínio, impulsionados pelos consumidores intermediários.

As negociações envolvendo jogadores também ocupam um papel de destaque nas receitas e despesas dos clubes, segundo o site oficial do São Paulo FC (2012) o atleta Lucas foi transferido ao Paris SaintGermain da França em 2012, pelo maior valor já pago a um clube brasileiro, $\square 43$ milhões (cerca de 108,3 milhões de reais).

Com o fortalecimento da economia brasileira os clubes deixaram de serem apenas grandes exportadores de jogadores e passaram a investir em reforços, segundo o site ESPN (2013) o Corinthians realizou a maior compra da história do futebol brasileiro, pagando $\square 15$ milhões (cerca de 40,5 milhões de reais) pelo atacante Alexandre Pato junto ao Milan da Itália.

Recentemente Somoggi (2013) destaca que entre 2003 e 2007 as receitas que mais contribuíram para o aumento da arrecadação dos clubes foram às transferências de atletas, ao passo que entre 2008 e 2011 as receitas que mais contribuíram foram às receitas com direito de transmissão de televisão e patrocínios e marketing, chegando a representar em 2011 mais de 50\% das receitas dos clubes. 
As receitas com direito de transmissão de televisão tiveram um salto exponencial nos últimos anos $\mathrm{e}$ projeta-se que estas cheguem num patamar ainda maior, pois até 2011 os direitos de transmissão eram negociados com o Clube dos 13 , entidade que representa os maiores clubes do Brasil e a partir do quadriênio 2012-2015 essas passarão a ser negociadas diretamente entre as emissoras e os clubes, o que possibilitará um maior poder de barganha por parte dos clubes para pleitear receitas ainda maiores.

Os clubes europeus de futebol apresentam além dessas fontes de arrecadação, a bolsa de valores para captação de recursos. "Alguns clubes europeus ultrapassaram o limite de clube-empresa ao aderirem o modelo de empresa societária, negociando ações em bolsas de valores, sendo a da Inglaterra a pioneira" (DANTAS et al., 2009, p. 56).

Em 1983 o Tottenham Hottspur foi o primeiro clube inglês a abrir capital na Bolsa de Londres, captando 9,2 milhões de libras, seguido pelo Manchester United em 1991. Em 2009 existiam 38 entidades esportivas de capital aberto em todo o mundo (DANTAS et al, 2009; DANTAS e BOENTE, 2011).

Percebe-se que na Europa vários clubes de futebol aderiram o modelo de Sociedades Anônimas, e que esse modelo vem se mostrando eficiente quanto a captação de recursos na Bolsa de Valores.

No Brasil, até o momento, não há nenhum clube com capital aberto na Bolsa de Valores, porém como visto anteriormente, para continuarem sendo competitivos como clube-empresa, a tendência é que utilizem esse modelo de gestão.

\section{A busca de transparência e eficiência em clubes de futebol}

Diante do grande interesse do brasileiro pelo futebol e do grande fluxo monetário movimentado por esse mercado, se fez necessária uma maior normatização e transparência das entidades desportivas.

Segundo Dantas e Boente (2011, p. 76) “com todas as mudanças de mercado que este esporte sofreu ao longo dos anos, surgiu à necessidade de se obter um maior conhecimento sobre as finanças dos principais clubes de um país".

Em 24 de março de 1998 foi publicada a Lei 9.615, popularmente conhecida como Lei Pelé, onde houve equiparação, em diversos pontos, entre as entidades esportivas e as sociedades anônimas, entre os quais se destacam a configuração da exploração do desporto profissional como atividade econômica, a obrigatoriedade das entidades esportivas elaborarem suas demonstrações financeiras, submetê-las a auditoria independente, nos termos da lei e de acordo com os critérios estabelecidos pelo Conselho Federal de Contabilidade e posteriormente publicá-las em meio eletrônico (BRASIL, 1998).

Os critérios tratados na Lei Pelé foram estabelecidos em 2004, por meio da Resolução CFC n. ${ }^{0} 1.005$ que aprovou a NBC T 10.13, que estabelece critérios e procedimentos contábeis para as entidades desportivas profissionais.

A partir desse momento os clubes de futebol passaram a efetivamente serem vistos como empresas, inclusive suas informações contábeis passaram a ser padronizadas e publicadas, o que contribui para a transparência de informações e o incremento de investidores.

Os futuros investidores analisam a eficiência da administração da empresa antes de aplicar seus recursos, eficiência esta definida como capacidade de obtenção máxima de resultados com o mínimo de insumos (HENDRIKSEN E BREDA, 1999, P. 202). Analogia similar pode ser feita aos clubes de futebol, pois com o mínimo de insumos, ou despesas, busca-se um retorno ótimo, seja por meio de receitas ou pontos ganhos em determinado campeonato, que resulte em conquista de título, meta almejada por todos os clubes.

Hendriksen e Breda (1999, p. 224) definem receitas e despesas como as engrenagens principais da empresa, porque sem despesas não haveria receita, pois aquelas contribuem para o processo de obtenção destas. Ao passo que, sem receitas não haveria o lucro, que é o objetivo principal das entidades e sem o lucro não haveria empresas. Dada essa definição, tornarse imprescindível o estudo pormenorizado dessas duas variáveis essenciais para sobrevivência de toda empresa.

Nesse contexto o modelo DEA se mostra uma ferramenta útil para se mensurar a eficiência, pois nem sempre o clube que foi campeão da temporada foi o mais eficiente, dados os insumos e produtos à disposição da administração. Por vezes um clube 
modesto que não possui tantos recursos à disposição, mesmo não se sagrando campeão de uma competição, pode ser o mais eficiente, dada sua capacidade de otimização das despesas para geração de receitas.

\section{Estudos similares sobre o tema}

Foi realizada uma busca no portal Capes, em periódicos da área contábil e nos anais do Congresso USP de contabilidade, com o objetivo de identificar estudos similares sobre o tema eficiência esportiva dos clubes de futebol. Como resultados destacaram-se quatro estudos similares.

Dantas et. al. (2009) realizaram estudo objetivando determinar o relacionamento entre a variável dependente - preços das ações do clube de futebol italiano Juventus F.C. - e as variáveis independentes - resultado semestral, endividamento, patrimônio líquido, ativo e passivo - por meio de análises de regressão. Os resultados evidenciam que as variáveis independentes não têm o poder de previsão eficiente e eficaz de explicar a variação dos preços das ações.

Pereira et. al. (2004) procuraram responder em seu estudo qual a relação existente entre o desempenho esportivo e o desempenho econômico-financeiro dos clubes de futebol que participaram do campeonato brasileiro de 2001 e 2002, para tanto, analisaram o volume de receitas, de custos e de despesas e a sua correlação com a posição do clube no campeonato.

O estudo apresentou como resultado um grau de correlação significativo entre as variáveis estudadas, sugerindo que a performance esportiva dos clubes estaria diretamente relacionada ao seu desempenho financeiro.

Dantas e Boente (2011) desenvolveram estudo onde analisaram a eficiência das despesas operacionais dos maiores clubes do futebol europeu, confrontando-as com as receitas totais para evidenciarem-se os aspectos financeiros e com o aproveitamento percentual dos pontos disputados no período para evidenciar os aspectos esportivos, com o uso da Análise Envoltória de Dados - DEA.

Os resultados da pesquisa demonstram que o Manchester United que foi o time que teve a melhor arrecadação de receitas em relação às despesas também foi time com melhor eficiência esportiva no período, e que o Newcastle que foi o time menos eficiente financeiramente, gastou $36 \%$ a mais do arrecadou, também foi o menos eficiente esportivamente sendo rebaixado do campeonato inglês no período.

Há que se destacar também que no mesmo estudo o Werder Bremen, clube alemão de menor expressão, também foi considerado eficiente quando considerado apenas os aspectos financeiros, pois o uso da Análise Envoltória de Dados - DEA modelo BCC, ao apresentar um retorno de escala variável de análise, propicia que clubes com menor arrecadação possam otimizar seus gastos, tornando-se eficientes financeiramente.

Em pesquisa desenvolvida por Assis e Silva (2012) a gestão financeira dos 12 clubes de futebol mais populares do Brasil foi estudada, objetivando interpretar e analisar as demonstrações contábeis em confronto com os resultados atingidos em competições, utilizando para tal alguns índices de estrutura de capital, de liquidez e rentabilidade e a pontuação total nos campeonatos brasileiros de 2007 a 2011.

Como resultado obteve-se que as duas equipes que mostraram ter a melhor situação financeira, São Paulo e Corinthians, foram equipes que mantiveram também excelentes resultados esportivos, evidenciouse também que o único índice que não manteve relação com os resultados esportivos foi o índice de composição do endividamento, demonstrando que as dívidas de curto prazo não interferiram nos resultados dentro de campo.

Observa-se a partir dos resultados dos estudos anteriores que a eficiência financeira dos clubes está fortemente relacionada com os seus resultados esportivos, pois na maioria das vezes o clube com melhores resultados financeiros também obteve os melhores resultados esportivos.

Sobre este estudo, tem-se como diferencial a possibilidade de após a análise da fronteira de eficiência dos clubes de futebol do Campeonato Brasileiro de 2012, definir os targets (metas), a nova classificação final do Campeonato Brasileiro Série "A" de 2012, considerando-se as receitas geradas e as despesas realizadas. 


\section{Metodologia}

\section{Classificação da pesquisa}

Segundo Vergara (2000) esta pesquisa foi classificada quanto a sua finalidade e meios. Quanto à finalidade foi considerada exploratória, descritiva e metodológica, pois existem poucas publicações sobre o assunto, apresenta características de determinada população e refere-se à manipulação da realidade. Quanto aos meios foi considerada como bibliográfica e documental, pois foi sistematizada e desenvolvida com base em material publicado, coletados nas demonstrações de resultado do exercício dos clubes.

Sobre a abordagem do problema utilizou-se a classificação de Silva e Menezes (2001), que foi considerada como quantitativa, uma vez que foi utilizado o modelo DEA - modelo baseado em programação matemática e não paramétrica - para a análise dos dados visando o cálculo e a evidenciação da fronteira de eficiência. Dessa forma, este estudo também é classificado como positivista uma vez que objetiva a apresentação de fatos e estabelecer relação entre eles, a partir do modelo DEA.

\section{Universo pesquisado e variáveis utilizadas}

Para realizar a pesquisa são analisados todos os 20 clubes de futebol que participaram do Campeonato Brasileiro Série "A" de 2012. Com relação às variáveis utilizadas, o montante das receitas e despesas foi extraído das demonstrações contábeis - Demonstrações do Resultado do Exercício - dos clubes de futebol no ano de 2012 por meio de seus respectivos sites oficiais. Já a pontuação final dos clubes foi extraída do site da Confederação Brasileira de Futebol (CBF). A tabela 1 apresenta esses dados:

Tabela 1 . Despesas, Receitas e Pontos dos Clubes de Futebol no Campeonato Brasileiro de 2012

\begin{tabular}{|c|c|c|c|c|}
\hline RK & CLUBES & DESPESAS $^{1}$ & RECEITAS $^{1}$ & PONTOS \\
\hline $1^{o}$ & Fluminense Football Club & 154.893 & 151.177 & 77 \\
\hline $2^{\circ}$ & Clube Atlético Mineiro & 196.165 & 162.963 & 72 \\
\hline $3^{\circ}$ & Grêmio Foot-ball Porto Alegrense ${ }^{2}$ & 211.624 & 239.807 & 71 \\
\hline $4^{\circ}$ & São Paulo Futebol Clube & 282.067 & 282.893 & 66 \\
\hline $5^{\circ}$ & Club de Regatas Vasco da Gama & 139.682 & 139.430 & 58 \\
\hline $6^{\circ}$ & Sport Club Corinthians Paulista & 303.379 & 310.917 & 57 \\
\hline $7^{\circ}$ & Botafogo de Futebol e Regatas & 172.701 & 123.421 & 55 \\
\hline $8^{\circ}$ & Santos Futebol Clube & 183.247 & 197.837 & 53 \\
\hline $9^{\circ}$ & Cruzeiro Esporte Clube & 151.359 & 120.363 & 52 \\
\hline $10^{\circ}$ & Sport Club Internacional & 251.800 & 264.193 & 52 \\
\hline $11^{\circ}$ & Clube de Regatas Flamengo & 272.504 & 212.019 & 50 \\
\hline $12^{\circ}$ & Clube Náutico Capibaribe & $*$ & $*$ & 49 \\
\hline $13^{\circ}$ & Coritiba Foot Ball Club & 90.936 & 82.757 & 48 \\
\hline
\end{tabular}




\begin{tabular}{|c|c|c|c|c|}
\hline $14^{\circ}$ & Associação Atlética Ponte Preta & 46.924 & 30.100 & 48 \\
\hline $15^{\circ}$ & Esporte Clube Bahia & 69.708 & 66.641 & 47 \\
\hline $16^{\circ}$ & Associação Portuguesa de Desporto & 48.829 & 50.283 & 45 \\
\hline $17^{\circ}$ & Sport Club do Recife & 56.266 & 79.808 & 41 \\
\hline $18^{\circ}$ & Sociedade Esportiva Palmeiras & 212.773 & 244.637 & 34 \\
\hline $19^{\circ}$ & Atlético Clube Goianiense & 36.620 & 23.408 & 30 \\
\hline $20^{\circ}$ & Figueirense Futebol Clube & 48.847 & 41.030 & 30 \\
\hline
\end{tabular}

Fonte: Elaborado pelos Autores

Legenda:

RK - Ranking

1 - Em milhares de Reais

2 - Suas demonstrações contábeis não foram auditadas

Para este estudo, excluiu-se do universo pesquisado o Clube Náutico Capibaribe, uma vez que as suas demonstrações contábeis não foram publicadas em seu site oficial.

\section{Modelo DEA como instrumento de pesquisa}

A análise envoltória de dados (DEA), consiste em um método quantitativo e não-paramétrico, baseada em programação matemática, que mede o desempenho relativo de unidades organizacionais semelhantes, por meio da construção de uma fronteira de eficiência (onde se encontram as unidades benchmarks), a partir da relação ponderada entre insumos (inputs) e produtos (outputs).

O método DEA apresenta dois modelos clássicos, um proposto por Charnes, Cooper e Rhodes em 1978 conhecido como CCR e um proposto por Banker, Charnes, Cooper em 1984 conhecido como BCC. A figura 1 representa os modelos CCR e BCC:

Figura 1. Fronteiras CCR e BCC

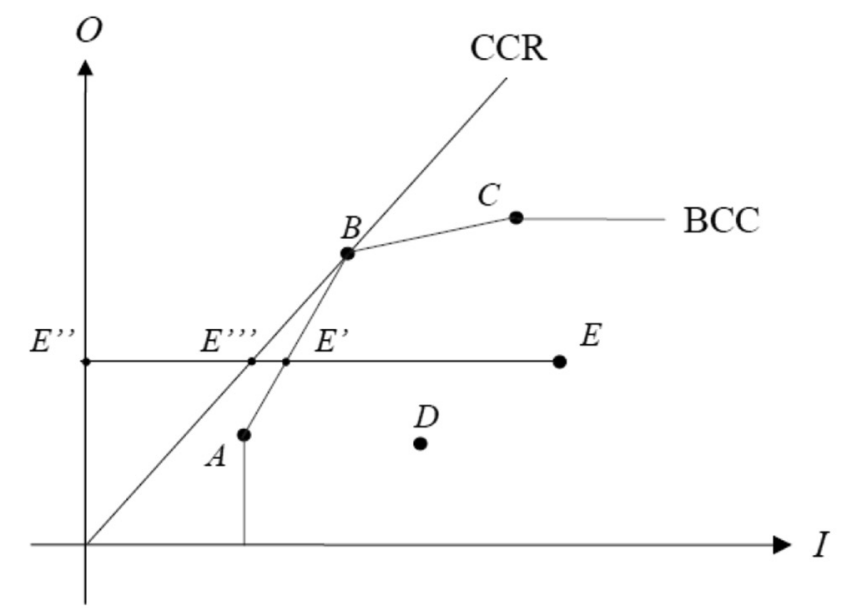

Fonte: Ângulo Meza et. al. (2005) 
Ambos os modelos apresentam ainda dois tipos de orientação, a input ou insumo e a output ou produto. A orientação a input busca minimizar as quantidades de insumos, isto é, busca a maior redução do consumo para a produção observada da empresa. Já a orientação a output busca-se maximizar os produtos dado o consumo observado da empresa (KASSAI, 2002).

O modelo CCR proposto por Charnes, Cooper e Rhodes (1978), também conhecido como CRS (Constant Returns to Scale), apresenta um retorno de escala constante de análise, ou seja, qualquer variação nas entradas (inputs) produz variação proporcional nas saídas (outputs). A seguir são apresentadas as fórmulas do modelo CCR:

Orientação a Input:

Maximizar $h_{k}=\sum_{r=1}^{s} u_{r} y_{r k}$,

sujeito a

$$
\begin{aligned}
& \sum_{r=1}^{m} u_{r} y_{r j}-\sum_{i=1}^{n} v_{i} x_{i j} \leq 0 \\
& \sum_{i=1}^{n} v_{i} x_{i k}=1 \\
& u_{r}, v_{i} \geq 0 \\
& y=\text { produtos } ; x=\text { insumos } ; u, v=\text { pesos } \\
& r=1, \ldots, m ; i=1, \ldots, n ; j=1, \ldots, N
\end{aligned}
$$

\section{Orientação a Output:}

Minimizar $h_{k}=\sum_{i=1}^{n} v_{i} x_{i k}$,

sujeito a

$$
\begin{aligned}
& \sum_{r=1}^{m} u_{r} y_{r j}-\sum_{i=1}^{n} v_{i} x_{i j} \leq 0 \\
& \sum_{r=1}^{m} u_{r} y_{r k}=1 \\
& u_{r}, v_{i} \geq 0 \\
& y=\text { produtos } ; \quad x=\text { insumos } ; u, v=\text { pesos } \\
& r=1, \ldots, m ; i=1, \ldots, n ; j=1, \ldots, N
\end{aligned}
$$

Ceretta e Niederauer (2000, apud KASSAI e ONUSIC, 2004) interpretam a formulação matemática do modelo CCR da seguinte forma:

\section{[...] considere-se $\mathrm{N}$ empresas} produzindo $\mathrm{m}$ quantidades de produtos y a partir de $n$ quantidades de insumos $x$. Uma empresa $k$ qualquer produz yrk quantidades de produtos com a utilização de xik quantidades de insumos. O objetivo da DEA é encontrar o máximo indicador de eficiência $\mathrm{hk}$ onde ur é o peso específico a ser encontrado para um produto $\mathrm{r}$ e vi o peso específico de cada insumo i.

O modelo BCC proposto por Banker, Charnes e Cooper (1984), também conhecido como VRS (Variable Returns to Scale), apresenta um retorno de escala variável de análise, ou seja, os retornos consideram que o acréscimo em uma unidade de insumo pode gerar um acréscimo não proporcional no volume de produtos. A seguir são apresentadas as fórmulas do modelo BCC:

Orientação a Input:

Maximizar $\sum_{r=1}^{m} u_{r} y_{r k}-u_{k}$,

sujeito a

$\sum_{i=1}^{n} v_{i} x_{i k}=1$

$\sum_{r=1}^{m} u_{r} y_{r j}-\sum_{i=1}^{n} v_{i} x_{i j}-u_{k} \leq 0$

$u_{r}, v_{i} \geq 0$

$y=$ produtos $; x=$ insumos $; u, v=$ pesos

$r=1, \ldots, m ; i=1, \ldots, n ; j=1, \ldots, N$ 
Orientação a Output:

Minimizar $\sum_{i=1}^{n} v_{i} x_{k i}+v_{k}$,

sujeito a

$$
\begin{aligned}
& \sum_{r=1}^{m} u_{r} y_{r k}=1 \\
& \sum_{r=1}^{m} u_{r} y_{j r}-\sum_{i=1}^{n} v_{i} x_{j i}-v_{k} \leq 0 \\
& u_{r}, v_{i} \geq 0 \\
& y=\text { produtos } ; \quad x=\text { insumos } ; u, v=\text { pesos } \\
& r=1, \ldots, m ; i=1, \ldots, n ; j=1, \ldots, N
\end{aligned}
$$

Para o presente estudo utilizou-se além da fronteira de eficiência DEA, onde se encontram as unidades benchmarks, a partir da relação ponderada entre insumos (inputs) e produtos (outputs), a fronteira invertida para a validação do modelo DEA, que consiste em montar uma espécie de fronteira de ineficiência, onde os inputs são considerados outputs, e os outputs são considerados inputs para a análise.

A fronteira invertida se mostra relevante, pois permite demonstrar qual das unidades tomadoras de decisão (DMUs), no caso os clubes de futebol, mais eficiente dentre as que se mantiveram empatadas na fronteira de eficiência padrão, identificando assim a chamada "falsa-eficiência"(NEVES JUNIOR et al., 2012).

A figura 2 mostra as duas fronteiras, a clássica e a invertida, para o modelo DEA-BCC:

Figura 2 . Fronteira de Eficiência Clássica e Invertida

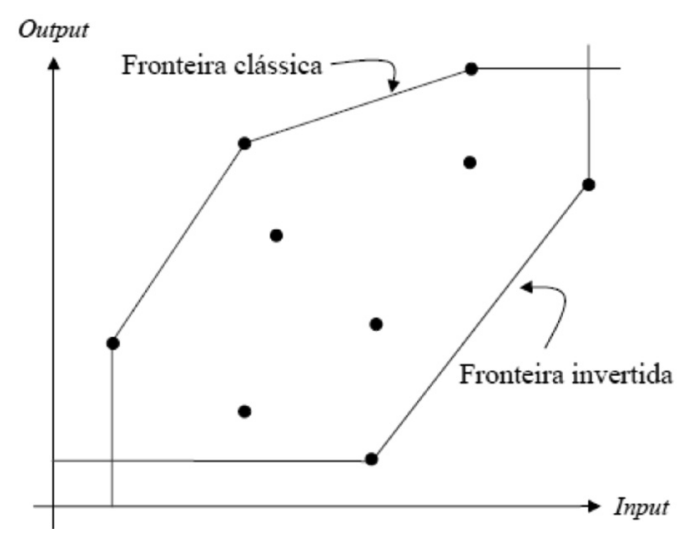

Fonte: Mello et. al. (2005)
Nesse sentido, uma maneira de se construir um ranking de eficiência, é por meio do cálculo da fronteira de eficiência composta e da fronteira de eficiência normalizada.

Segundo Leta et al. (2005) "para ordenar as DMUs é, então, calculado um índice de eficiência agregado, que é a média aritmética entre a eficiência em relação à fronteira original e a ineficiência (1 menos a eficiência) em relação à fronteira invertida". Conforme fórmula a seguir:

Eficiência Composta $=$ Eficiência Padrão $+(1-$ Eficiência Invertida) / 2

Ainda segundo Leta et al. (2005) "este índice pode ser apresentado de forma normalizada, para o qual, basta dividir todos os valores pelo maior índice calculado". Conforme fórmula a seguir:

Eficiência Normalizada = Eficiência Composta / Max (Eficiência Composta)

\section{Delineando o modelo DEA para aplicação nesta pesquisa}

O modelo DEA utilizado na pesquisa foi o BCC (Banker, Charnes, Cooper), também conhecida como VRS (Variable Returns to Scale) que apresenta um retorno de escala variável de análise e foi utilizada orientação para output, ou seja, optou-se por maximizar os produtos. Foi realizada a orientação a output para estudar a eficiência esportiva dos clubes, onde a partir dos gastos realizados, são maximizadas as receitas geradas e os pontos obtidos no campeonato em questão.

As variáveis de entrada e saída foram escolhidas em consonância com o problema de pesquisa. Para tanto foi utilizada como input/insumo a despesa, que compreende: despesas compessoale encargos, despesas com vendas e aquisição de atletas, despesas com gratificações e bonificações, despesa com pagamento de direitos de imagem e de arena, amortização de atletas profissionais, despesas administrativas e depreciações. Como outputs/produtos utilizou-se as receitas, que compreendem: a arrecadação com bilheteria de jogos, direitos de transmissão de televisão, repasse de direitos federativos, receitas com publicidade e patrocínio, receitas com premiações e loteria, receitas 
com aluguel, receitas com projeto sócio torcedor e receitas com licenciamento da marca; e a pontuação final no Campeonato Brasileiro Série "A" de 2012.

\section{Procedimentos}

A pesquisa foi estruturada em três partes, sendo elas: definição; coleta e análise dos dados e resultados.

$\mathrm{Na}$ definição, foi estabelecido que seriam estudados os clubes de futebol brasileiros e delineou-se que a análise seria feita pelo modelo DEA utilizando-se a escala de retorno variável.

Na coleta e análise dos dados, extraíram-se os dados da Demonstração do Resultado do Exercício do ano de 2012 disponíveis nos sites oficiais dos clubes de futebol e foi feita a análise com a aplicação do modelo DEA com o auxílio do software SIAD v.3.0.

Nos resultados, foi feita a análise da fronteira de eficiência dos clubes de futebol brasileiros, assim como, o ranking de eficiência, onde são apresentados os clubes considerados eficientes e as metas de melhoria para os clubes considerados ineficientes. Posteriormente foi definido, através do ranking de eficiência, qual seria a classificação final do Campeonato Brasileiro Série "A" de 2012 após análise DEA.

\section{Resultados}

\section{Análise do ranking de eficiência}

Com base nos dados apresentados na tabela 1, aplicou-se o modelo de Análise Envoltória de Dados, como o auxílio do software SIAD v.3 (Sistema Integrado de Apoio a Decisão) utilizando o modelo BCC como orientação a Output.

A tabela 2 mostra os resultados obtidos com a análise DEA, contendo os escores de eficiência das fronteiras padrão, invertida, composta e normalizada, respectivamente.

Tabela 2 . Ranking de eficiência.

\begin{tabular}{|c|c|c|c|c|c|}
\hline Posição & DMU & PADRÃO & INVERTIDA & COMPOSTA & NORMALIZADA \\
\hline $1^{\circ}$ & Grêmio & $100,0 \%$ & $67,3 \%$ & $66,3 \%$ & $100,0 \%$ \\
\hline $2^{\circ}$ & Portuguesa & $100,0 \%$ & $68,6 \%$ & $65,7 \%$ & $99,0 \%$ \\
\hline $3^{\circ}$ & Fluminense & $100,0 \%$ & $72,9 \%$ & $63,5 \%$ & $95,8 \%$ \\
\hline $4^{\circ}$ & Sport & $100,0 \%$ & $73,6 \%$ & $63,2 \%$ & $95,2 \%$ \\
\hline $5^{\circ}$ & Bahia & $92,6 \%$ & $73,2 \%$ & $59,7 \%$ & $89,9 \%$ \\
\hline $6^{\circ}$ & Vasco & $90,8 \%$ & $73,9 \%$ & $58,4 \%$ & $88,0 \%$ \\
\hline $7^{\circ}$ & Santos & $93,6 \%$ & $77,0 \%$ & $58,3 \%$ & $87,8 \%$ \\
\hline $8^{\circ}$ & São Paulo & $100,0 \%$ & $85,8 \%$ & $57,1 \%$ & $86,1 \%$ \\
\hline $9^{\circ}$ & Internacional & $97,1 \%$ & $85,4 \%$ & $55,8 \%$ & $84,1 \%$ \\
\hline $10^{\circ}$ & Coritiba & $85,7 \%$ & $78,4 \%$ & $53,7 \%$ & $80,9 \%$ \\
\hline $11^{\circ}$ & Atlético Mineiro & $95,2 \%$ & $88,5 \%$ & $53,3 \%$ & $80,4 \%$ \\
\hline $12^{\circ}$ & Corinthians & $100,0 \%$ & $100,0 \%$ & $50,0 \%$ & $75,4 \%$ \\
\hline $13^{\circ}$ & Ponte Preta & $100,0 \%$ & $100,0 \%$ & $50,0 \%$ & $75,4 \%$ \\
\hline
\end{tabular}




\begin{tabular}{|c|c|c|c|c|c|}
\hline $14^{\circ}$ & Palmeiras & $100,0 \%$ & $100,0 \%$ & $50,0 \%$ & $75,4 \%$ \\
\hline $15^{\circ}$ & Atlético Goianiense & $100,0 \%$ & $100,0 \%$ & $50,0 \%$ & $75,4 \%$ \\
\hline $16^{\circ}$ & Cruzeiro & $75,1 \%$ & $91,4 \%$ & $41,9 \%$ & $63,1 \%$ \\
\hline $17^{\circ}$ & Flamengo & $76,0 \%$ & $100,0 \%$ & $38,0 \%$ & $57,3 \%$ \\
\hline $18^{\circ}$ & Figueirense & $74,5 \%$ & $100,0 \%$ & $37,2 \%$ & $56,1 \%$ \\
\hline $19^{\circ}$ & Botafogo & $72,6 \%$ & $100,0 \%$ & $36,3 \%$ & $54,7 \%$ \\
\hline
\end{tabular}

Fonte: Elaborado pelos Autores

A fronteira de eficiência padrão foi composta pelos seguintes clubes: Grêmio, Portuguesa, Fluminense, Sport, São Paulo, Corinthians, Ponte Preta, Palmeiras e Atlético Goianiense. Como destacado por Neves Júnior et al. (2012), sobre a ótica da eficiência padrão esses nove clubes se mantiveram empatados.

Como um dos objetivos do presente estudo é construir um ranking de eficiência, utilizamos a fronteira de eficiência invertida para validação do modelo DEA, a fronteira invertida possibilitou identificar os clubes que foram considerados eficientes na fronteira padrão, porém representam uma falsa eficiência ao considerarmos inputs como outputs e vice-versa.

Ao utilizar a fronteira de eficiência invertida esperava-se que todas as empresas que foram consideradas eficientes na fronteira padrão passassem ao status de ineficientes na fronteira invertida, porém isso não ocorreu, Corinthians, Ponte Preta, Palmeiras e Atlético Goianiense apresentaram escores de 100\% também para a fronteira invertida confirmando mais uma vez o exposto na fundamentação teórica do modelo DEA sobre a ocorrência de DMUs com "falsas eficiências".

Dessa maneira, atingimos um dos objetivos específicos, que consiste em construir o ranking de eficiência, pois ao identificar as empresas com "falsa eficiência" conseguimos desempatar as empresas, que apresentavam escore de 100\% na fronteira de eficiência padrão.

Para a construção do ranking calculou-se a fronteira composta e a fronteira normalizada, para a partir da fronteira de eficiência normalizada seja possível inferir que o Grêmio foi o clube que empregou de maneira mais eficiente seus insumos (despesas), em relação a obtenção de seus produtos (receitas e pontuação).

Em segundo lugar no ranking de eficiência ficou a Portuguesa com 99,0\% de eficiência, clube em que suas receitas e despesas representam respectivamente 20,96\% e 23,07\% das receitas e despesas do Grêmio e que na classificação final do Campeonato Brasileiro de 2012 figurou apenas na 16ª colocação.

Esse resultado corrobora com os achados da pesquisa de Dantas e Boente (2011), onde um clube de menor expressão também foi considerado eficiente, pois o modelo BCC ao apresentar uma escala de retorno variável, propicia que clubes com menores receitas possam otimizar suas despesas e sua pontuação, tornando-se eficientes.

Os quatro clubes menos eficientes no período analisado foram: Cruzeiro (63,1\%), Flamengo (57,3\%), Figueirense $(56,1 \%)$ e Botafogo (54,7\%). Ao confrontarmos esse resultado com os dados da Tabela 1, verificamos que entre os quatro clubes menos eficientes, apenas o Figueirense figurava entre os quatro últimos com menos pontuação no Campeonato Brasileiro Série "A" de 2012.

O Corinthians que registrou em suas demonstrações contábeis a maior receita e a maior despesa entre os clubes analisados, se mostrou pouco eficiente, com $75,4 \%$ de eficiência, figurando em $12^{\circ}$ lugar no ranking de eficiência normalizada.

No entanto, ao contrastar os resultados desta pesquisa com os de Dantas e Boente (2011), foi possível identificar que, os resultados divergem, pois no estudo desses pesquisadores o clube de maior arrecadação também foi o clube com melhor eficiência esportiva. 


\section{Metas para melhoria}

A partir da fronteira de eficiência padrão, o Modelo DEA definiu metas (targets) de melhoria para as empresas consideradas ineficientes. No período analisado, essas metas, caso atingidas, permitiriam que as empresas ineficientes se tornassem eficientes. A tabela 3 apresenta essas metas.

Tabela 3 . Metas para melhoria

\begin{tabular}{|c|c|c|c|c|c|c|c|c|c|}
\hline \multirow{2}{*}{ CLUBES } & \multicolumn{3}{|c|}{ DESPESAS } & \multicolumn{3}{|c|}{ RECEITAS } & \multicolumn{3}{|c|}{ PONTUAÇÃO } \\
\hline & Atual & $\Delta \%$ & Meta & Atual & $\Delta \%$ & Meta & Atual & $\Delta \%$ & Meta \\
\hline Fluminense & $154.893,00$ & - & $154.893,00$ & $151.177,00$ & - & $151.177,00$ & 77,00 & - & 77,00 \\
\hline Grêmio & $211.624,00$ & - & $211.624,00$ & $239.807,00$ & - & $239.807,00$ & 71,00 & - & 71,00 \\
\hline São Paulo & $282.067,00$ & - & $282.067,00$ & $282.893,00$ & - & $282.893,00$ & 66,00 & - & 66,00 \\
\hline Corinthians & $303.379,00$ & - & $303.379,00$ & $310.917,00$ & - & $310.917,00$ & 57,00 & - & 57,00 \\
\hline Ponte Preta & $46.924,00$ & - & $46.924,00$ & $30.100,00$ & - & $30.100,00$ & 48,00 & - & 48,00 \\
\hline Portuguesa & $48.829,00$ & - & $48.829,00$ & $50.283,00$ & - & $50.283,00$ & 45,00 & - & 45,00 \\
\hline Sport & $56.266,00$ & - & $56.266,00$ & $79.808,00$ & - & $79.808,00$ & 41,00 & - & 41,00 \\
\hline Palmeiras & $212.773,00$ & - & $212.773,00$ & $244.637,00$ & - & $244.637,00$ & 34,00 & - & 34,00 \\
\hline Atlético Goianiense & $36.620,00$ & - & $36.620,00$ & $23.408,00$ & - & $23.408,00$ & 30,00 & - & 30,00 \\
\hline Internacional & $251.800,00$ & - & $251.800,00$ & $264.193,00$ & 3,01 & $272.152,57$ & 52,00 & 3,00 & 53,56 \\
\hline Atlético Mineiro & $196.165,00$ & $-14,50$ & $167.716,07$ & $162.963,00$ & 5,06 & $171.210,29$ & 72,00 & 5,05 & 75,64 \\
\hline Santos & $183.247,00$ & - & $183.247,00$ & $197.837,00$ & 6,88 & $211.451,59$ & 53,00 & 6,86 & 56,64 \\
\hline Bahia & $69.708,00$ & - & $69.708,00$ & $66.641,00$ & 8,04 & $72.003,70$ & 47,00 & 8,04 & 50,78 \\
\hline Vasco & $139.682,00$ & - & $139.682,00$ & $139.430,00$ & 10,17 & $153.614,87$ & 58,00 & 10,17 & 63,90 \\
\hline Coritiba & $90.936,00$ & - & $90.936,00$ & $82.757,00$ & 16,63 & $96.522,04$ & 48,00 & 16,62 & 55,98 \\
\hline Flamengo & $272.504,00$ & - & $272.504,00$ & $212.019,00$ & 31,53 & $278.871,66$ & 50,00 & 31,52 & 65,76 \\
\hline Cruzeiro & $151.359,00$ & - & $151.359,00$ & $120.363,00$ & 33,09 & $160.198,91$ & 52,00 & 33,09 & 69,21 \\
\hline Figueirense & $48.847,00$ & - & $48.847,00$ & $41.030,00$ & 34,24 & $55.078,84$ & 30,00 & 34,23 & 40,27 \\
\hline Botafogo & $172.701,00$ & $-3,35$ & $166.902,43$ & $123.421,00$ & 37,69 & $169.939,16$ & 55,00 & 37,67 & 75,72 \\
\hline
\end{tabular}

Fonte: Elaborado pelos Autores

Legenda: $\Delta \%$ - Variação Percentual

Por terem sido considerados eficientes na fronteira de eficiência padrão, Fluminense, Grêmio, São Paulo, Corinthians, Ponte Preta, Portuguesa, Sport, Palmeiras e Atlético Goianiense, não precisariam mudar suas receitas, despesa e sua pontuação, pois os mesmos já se encontram sobre a fronteira de eficiência.

O Internacional, que no período foi o clube que ficou mais próximo de alcançar a fronteira com 97,1\%, por consequência também foi o clube que teve as menores metas de melhoria, para alcançar a fronteira precisaria aumentar em 3,01\% as suas receitas e em 3\% sua pontuação no campeonato. A variável despesa se manteria inalterada.

Já o clube Atlético Mineiro para alcançar a fronteira teria que aumentar suas receitas em 5,06\% e sua pontuação em 5,05\%. Paralelamente a esse aumento ainda teria que diminuir suas despesas em 14,5\%.

Os dois clubes menos eficientes na fronteira de eficiência padrão também foram os menos eficientes na fronteira de eficiência normalizada, por esse motivo, Figueirense e Botafogo tiveram as maiores metas de melhoria em termos percentuais. 
Para alcançar a fronteira de eficiência o Figueirense deveria aumentar em 34,24\% suas receitas e em 34,23\% sua pontuação.

Já o Botafogo teve como meta de melhoria aumentar em 37,69\% suas receitas e em 37,67\% sua pontuação. Adicionalmente, deve ainda diminuir em 3,35\% suas despesas.

O Flamengo mesmo não sendo o menos eficiente entre os clubes analisados, é o clube que mais deve aumentar suas receitas em valores absolutos, deve incrementar suas receitas em aproximadamente $\mathrm{R} \$ 66.852 .000,00$.

É importante destacar que o software SIAD v.3 limita-se a definir metas de melhoria baseando-se apenas na fronteira de eficiência padrão, portanto clubes como Corinthians, Ponte Preta, Palmeiras e Atlético Goianiense, que alcançaram apenas $75,4 \%$ de eficiência, quando considerada a fronteira de eficiência normalizada, não apresentam metas de melhorias.

\section{Classificação após análise DEA}

A partir das metas de melhorias apresentadas na tabela 3, elaborou-se um comparativo entre a classificação do Campeonato Brasileiro Série "A" de 2012 antes e após a análise DEA.

Para efeito desta análise, não foi considerado o Clube Náutico Capibaribe, uma vez que o mesmo não publicou suas demonstrações contábeis.

Devido a esse fato, excluiu-se o Náutico da análise dos dados antes e após a aplicação do modelo DEA.

Tabela 4 . Classificação antes e após análise DEA

\begin{tabular}{|c|c|c|c|c|c|}
\hline \multicolumn{3}{|c|}{ CLASSIFICAÇÃO ANTES DA ANÁLISE DEA } & \multicolumn{3}{|c|}{ CLASSIFICAÇÃO APÓS ANÁLISE DEA } \\
\hline RK & CLUBES & PONTOS & RK & CLUBES & PONTOS \\
\hline $1^{o}$ & Fluminense & 77 & $1^{o}$ & Fluminense & 77 \\
\hline $2^{\circ}$ & Atlético Mineiro & 72 & $2^{\circ}$ & Botafogo & 76 \\
\hline $3^{\circ}$ & Grêmio & 71 & $3^{\circ}$ & Atlético Mineiro & 76 \\
\hline $4^{\circ}$ & São Paulo & 66 & $4^{\circ}$ & Grêmio & 71 \\
\hline $5^{\circ}$ & Vasco & 58 & $5^{\circ}$ & Cruzeiro & 69 \\
\hline $6^{\circ}$ & Corinthians & 57 & $6^{\circ}$ & São Paulo & 66 \\
\hline $7^{\circ}$ & Botafogo & 55 & $7^{\circ}$ & Flamengo & 66 \\
\hline $8^{\circ}$ & Santos & 53 & $8^{\circ}$ & Vasco & 64 \\
\hline $9^{\circ}$ & Cruzeiro & 52 & $9^{\circ}$ & Corinthians & 57 \\
\hline $10^{\circ}$ & Internacional & 52 & $10^{\circ}$ & Santos & 57 \\
\hline $11^{\circ}$ & Flamengo & 50 & $11^{\circ}$ & Coritiba & 56 \\
\hline $12^{\circ}$ & Coritiba & 48 & $12^{\circ}$ & Internacional & 54 \\
\hline $13^{\circ}$ & Ponte Preta & 48 & $13^{\circ}$ & Bahia & 51 \\
\hline
\end{tabular}




\begin{tabular}{|c|c|c|c|c|c|}
\hline $14^{\circ}$ & Bahia & 47 & $14^{\circ}$ & Ponte Preta & 48 \\
\hline $15^{\circ}$ & Portuguesa & 45 & $15^{\circ}$ & Portuguesa & 45 \\
\hline $16^{\circ}$ & Sport & 41 & $16^{\circ}$ & Sport & 41 \\
\hline $17^{\circ}$ & Palmeiras & 34 & $17^{\circ}$ & Figueirense & 40 \\
\hline $18^{\circ}$ & Atlético Goianiense & 30 & $18^{\circ}$ & Palmeiras & 34 \\
\hline $19^{\circ}$ & Figueirense & 30 & $19^{\circ}$ & Atlético Goianiense & 30 \\
\hline
\end{tabular}

Fonte: Elaborado pelos Autores

Legenda: RK - Ranking

Com base nesses dados, podemos inferir que Fluminense seria o maior pontuador do campeonato em questão, mesmo se levássemos em consideração suas despesas realizadas e suas receitas arrecadadas em 2012.

O Botafogo deixaria a sétima colocação e subiria para segunda colocação no campeonato, pois como meta deveria aumentar sua pontuação em $37,67 \%$ passando dos atuais 55 pontos para 76 pontos.

Cruzeiro, nono colocado, e Flamengo, décimo primeiro colocado no Campeonato Brasileiro de 2012, subiriam quatro posições cada, passando respectivamente para quinta e sétimas posições após análise DEA.

O Vasco $\left(5^{\circ}\right)$ e o Corinthians $\left(6^{\circ}\right)$, foram os clubes que mais perderiam posições, três cada um, passando respectivamente para as oitavas e nonas posições após análise DEA.

As quatro últimas colocações continuaram quase inalteradas, Sport, Figueirense, Palmeiras e Atlético Goianiense se mantiveram nas últimas colocações, havendo apenas uma alteração, a do Figueirense que passou da última colocação para décima sétima após as metas.

Não houve alterações significativas na classificação antes e após a análise DEA, exceto pelo fato de Botafogo, Cruzeiro e Flamengo terem ganhado algumas colocações e terem ultrapassado Vasco e Corinthians na tabela de classificação, os demais clubes em sua maioria se mantiveram nas mesmas posições ou variaram uma posição para mais ou para menos.

\section{Considerações Finais}

O presente estudo teve por objetivo analisar quais clubes de futebol podem ser considerados eficientes no Campeonato Brasileiro Série "A" de 2012, através da aplicação da Análise Envoltória de Dados, considerandose as despesas como input e as receitas e pontuação como outputs.

O Grêmio foi considerado o clube mais eficiente e o Botafogo foi considerado o menos eficiente em 2012, quando considerados sua pontuação no campeonato em questão, as receitas geradas e as despesas realizadas.

Através dos resultados obtidos, pode-se considerar a questão de pesquisa resolvida e os objetivos alcançados, pois foi possível evidenciar o clube de futebol mais eficiente, construir o ranking de eficiência, definir e analisar as metas de melhoria e definir qual seria a classificação final do Campeonato Brasileiro Série "A" de 2012 após análise DEA, considerando-se as receitas geradas e as despesas realizadas.

Ao analisar a fronteira de eficiência pode-se constatar que o clube que foi campeão brasileiro em 2012 não foi o mais eficiente quando analisadas também suas receitas e despesas. 
Com base na classificação antes e após a aplicação do modelo DEA, pode-se perceber que não houve modificações significativas na tabela de classificação do Campeonato Brasileiro de Futebol Série "A" de 2012, apenas Botafogo, Cruzeiro e Flamengo tiveram mudanças significativas em suas pontuações.

Diante dessa constatação, pode-se inferir que a eficiência financeira, representada neste estudo pelas despesas realizadas e pelas receitas arrecadadas, está relacionada a eficiência esportiva, representada pela pontuação auferida no campeonato em questão.

Dessa forma, o estudo denota a possibilidade de acompanharmos o desempenho econômicofinanceiro dos clubes, a partir das demonstrações contábeis, como um instrumento de apoio à verificação da eficiência esportiva dos clubes. Ademais, se considerada a perspectiva de abertura de capital dos clubes brasileiros nas bolsas de valores, torna-se oportuno e evidente a contribuição deste estudo para a decisão de investimento.

É importante destacar que variáveis não financeiras poderiam impactar a eficiência econômico-financeira e esportiva dos clubes, entre elas, os dirigentes dos clubes, a comissão técnica dos clubes, a liderança do treinador etc.

Como sugestões para trabalhos futuros poderse-á tomar como base para a pontuação outros campeonatos, para ter a possibilidade de abranger um número maior de clubes. Pode-se incluir mais variáveis no modelo DEA, pois qualquer modificação nas variáveis também modificará o resultado final da análise. Fica também como sugestão a utilização de mais períodos para análise.

\section{Referências Bỉbliográficas}

ANGULO MEZA, L.; BIONDI NETO, L.; SOARES DE MELLO, J. C. C. B.; GOMES, E. G. ISYDS - Integrated System for Decision Support (SIAD - Sistema Integrado de Apoio à Decisão): a software package for data envelopment analysis model. Pesquisa Operacional, v. 25, (3), p. 493-503, 2005. Disponível em: <http://www.uff.br/decisao>. Acesso em: 10 mai. 2013.

ASSIS, Pedro Borges C G de; SILVA, Anderson de Azevedo. Gestão Financeira versus Resultados do Esporte: Uma análise comparativa nos 12 clubes mais populares do futebol brasileiro. Universidade Católica de Brasília, UCB, Brasília, 2012.

BANKER, R. D.; CHARNES, A.; COOPER, W. W. Some models for estimating technical and scale ineffi ciencies in data envelopment analysis. Management Science, v. 30, n. 9, p. 1078-1092, September 1984. Disponível em: < http://mansci.highwire.org/ content/30/9/1078.full.pdf + html>. Acesso em: 08 mar. 13.

\section{BDO. Indústria do Esporte Futebol, a maior} paixão dos brasileiros Potencial mercadológico atual. Disponível em: < http://www.bdobrazil.com. br/pt/publicacoes.html >. Acesso em: 21 mar. 2013.

BRASIL. Lei $\mathbf{n}^{\circ} \mathbf{9 . 6 1 5}$, de 24 de março de 1998.

Institui normas gerais sobre os desportos e dá outras providencias. Disponível em: < http:/ /www.planalto. gov.br/ccivil_03/leis/19615consol.htm>. Acesso em: 01 fev. 2013.

CHARNES, A; COOPER, W. W.; RHODES, E. Measuring the efficiency of decision making units. European Journal of Operational Research, 1978. Disponível em: < http://www. vwl.tuwien.ac.at/hanappi/Lehre/MSM2010/ Charnes 1978.pdf>. Acesso em 4 abr. 2013.

COUTINHO, Filipe. Receita mostra que clubes brasileiros crescem em ritmo chinês. Folha de São Paulo, Brasília. 08 dez. 2012. Disponível em: $<$ http://www1.folha.uol.com.br/esporte/1198104receita-mostra-que-clubes-brasileiros-crescem-emritmo-chines.shtml >. Acesso em: 28 fev. 2013.

DAMATO, Marcelo. Especial finanças dos clubes: Mais ricos e mais risco: Balanços mostram que clubes continuam batendo recordes de arrecadação, mas despesas crescem ainda mais rápido, jun. 2012. Disponível em: < http://www.lancenet. com.br/minuto/Especial-financas-clubes-ricosrisco_0 712728923.html>. Acesso em: 26 mar. 2013.

DANTAS, Marke Geisy da Silva; BOENTE, Diego Rodrigues. A eficiência financeira e esportiva dos maiores clubes de futebol europeus utilizando a análise envoltória de dados. Revista de Contabilidade e Organizações, Ribeirão Preto, v. 05, n. 13, p.76-90, dez. 2011. Disponível em: $<$ http://www.rco.usp.br/index.php/rco/article/ view/322/212>. Acesso em: 21 mar. 2013. 
DANTAS, Marke Geisy da Silva et al. O comportamento do preço das ações de clubes de futebol mediante a variação de aspectos contábeis: o estudo de caso do Juventus F.C. - Itália. Revista Ambiental Contábil, Natal, v. 2, n. 1, p.55-67, jun. 2009. Semestral. Disponível em: $<$ http://www.atena. org.br/revista/ojs-2.2.3-08/index.php/Ambiente/ article/view/795 >. Acesso em: 03 fev. 2013.

\section{ESPN. Corinthians supera próprios recordes} na compra mais cara do Brasil. Disponível em: $<$ http://espn.estadao.com.br/noticia/301626_ corinthians-supera-proprios-recordes-na-compramais-cara-do-brasil>. Acesso em: 14 mar. 2013.

HENDRIKSEN, Eldon S; BREDA, Michael F. Van.

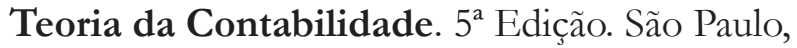
Atlas, 1999.

\section{INTERNATIONAL FEDERATION OF} FOOTBALL HISTORY \& STATISTICIS (Alemanha). The strongest National League in the World. Disponível em: < http://www.iffhs. de/?82c48d3171fd33400f06>. Acesso em: 01 mar. 2013.

\section{KASSAI, Silvia. Utilização da Análise por} Envoltória de Dados (DEA) na análise de demonstrações contábeis. 2002. 318 f. Tese (Doutorado) - Departamento de Faculdade de Economia, Administração e Contabilidade, Usp, São Paulo, 2002. Disponível em: < $\underline{\text { http://www. }}$ teses.usp.br/teses/disponiveis/12/12136/tde.../ TeseCompleta.pdf>. Acesso em: 09 maio 2013.

KASSAI, Silvia; ONUSIC, Luciana Massaro. Modelos de Previsão de Insolvência utilizando a Análise por Envoltória de Dados: aplicação a empresas brasileiras. 2004. In.: Congresso de Controladoria e Auditoria USP, 2004, São Paulo. Anais ... . São Paulo: 2004. Disponível em: $<$ http://www.congressousp.fipecafi.org/web/ artigos42004/137.pdf> . Acesso em: 01 maio 2013.

LETA, Fabiana Rodrigues et al. Métodos de Melhora de Ordenação em DEA Aplicados à Avaliação Estática de Tornos Mecânicos. Revista Investigação Operacional, Lisboa, v. 25, p.229242, 2005. Disponível em: <http://apdio.pt/ documents $/ 10180 / 15546 / \mathrm{n} 4$.pdf $>$. Acesso em: 09 set. 2013.
MELLO, João Carlos Correia Baptista Soares de et al. Curso de análise de envoltória de dados. In. Simpósio Brasileiro de Pesquisa Operacional, 37. 2005, Gramado. Anais... . Rio Grande do Sul: 2005. Disponível em: < http://www.uff.br/decisao/ $>$. Acesso em: 02 fev. 2013.

NEVES JÚNIOR, Idalberto José Das et al. Análise da eficiência na geração de retorno aos acionistas das empresas do setor da construção civil com ações negociadas na BM\&FBOVESPA nos anos de 2009 e 2010 por meio da análise envoltória de dados. Revista Contemporânea de Contabilidade, Florianópolis, v. 9, n. 18, p.41-62, 14 dez. 2012. Semestral. Disponível em: $<$ https://periodicos.ufsc. $\mathrm{br} /$ index.php/contabilidade/article/view/21758069.2012v9n18p41/23471>. Acesso em: 05 maio 2013.

PEREIRA, Carlos Alberto et al. A Gestão Estratégica de Clubes de Futebol: Uma Análise da Correlação Entre Performance Esportiva e Resultado Operacional. In: Congresso USP de Controladoria e Contabilidade, 4., 2004, São Paulo. Anais... . São Paulo: 2004. Disponível em: < http://www. congressousp.fipecafi.org/web/artigos42004/336. pdf>. Acesso em: 05 fev. 2013.

\section{SÃO PAULO FC. São Paulo FC vende Lucas} para o PSG por valor recorde. Disponível em: $<$ http://www.saopaulofc.net/noticias/noticias/ futebol/2012/8/8/sao-paulo-fc-vende-lucas-para-opsg-por-valor-recorde/>. Acesso em: 14 mar. 2013.

SILVA, Cláudio Vicente Di Gioia Ferreira; CAMPOS FILHO, Luiz Alberto Nascimento. Gestão de Clubes de Futebol Brasileiros: Fontes Alternativas de Receita. Revista Sistemas \& Gestão: Programa de Pós-graduação em Sistemas de Gestão, TEP/TCE/CTC/PROPP/UFF, Rio de Janeiro, v. 1, n. 3, p.195-209, dez. 2006. Disponível em: $<$ http://www.uff.br/sg/index.php/sg/article/view/ SGV1N3A2>. Acesso em: 02 mar. 2013.

SILVA, Edna Lúcia da; MENEZES, Estera Muszkat. Metodologia da Pesquisa e Elaboração de

Dissertação. 3. ed. Florianópolis: Laboratório de Ensino A Distância da UFSC/PPGEP, 2001. 121 p. Disponível em: < http://moodle.catolicavirtual. br/course $/$ view.php?id=5566 $>$. Acesso em: 07 mar. 2013. 
SOMOGGI, Amir. Análise Prévia: Finanças dos maiores clubes brasileiros em 2012, mai. 2013.

Disponível em: < http://www.ibdd.com.br/arquivos/

Financas $\% 20$ Clubes $\% 20$ Brasileiros $\% 20-\% 20$

Amir\%20Somoggi\%20-Maio\%202013.pdf>. Acesso em: 20 maio 2013.

\section{RODRIGUES, Bruno. Há 80 anos, São Paulo} goleava o Santos em primeiro jogo de futebol profissional do Brasil. Disponível em: $<\underline{\mathrm{http}}: / /$

www.lancenet.com.br/minuto/Paulo-Santos-futebolprofissional-Brasil 0 881311864.html>. Acesso em: 12 mar. 2013.

UNZELTE, Celso. Futebol a.C. (antes de Charles Miller): Antes da primeira bola oficial e das regras, a redonda já rolava havia tempos no Brasil. Disponível em: < http://guiadoestudante.abril. com.br/aventuras-historia/futebol-c-antes-charlesmiller-645015.shtml>. Acesso em: 26 fev. 2013.

VERGARA, S. C. Projetos e relatórios de pesquisa em administração. São Paulo: Atlas, 2000 . 